\title{
The Role of Knowledge about the L2 Code in Adult Second Language Acquisition: A Review of Theories and Research
}

Carol A. Fraser

This article reviews theories and research on the topic of the role of L/2 code knowledge in adult second language acquisition. In the literature, this issue has been addressed from two main theoretical perspectives-cognitive psychology, which examines the internal processing mechanisms involved in learning and then in using language information for communication, and second language acquisition, which examines the effects of instruction that focuses on the L2 code on the learner's developing L2 proficiency. This analysis concludes that while the knowledge the learner has about the L2 code plays a limited role (planning and monitoring) in actual communication, it does play a significant role in the development of proficiency. Finally, instructional implications emerging from existing theory and research data are drawn.

What role does the knowledge a second language learner has about the $\mathrm{L} 2$ code $^{1}$ play in developing proficiency, that is, the ability to use the L2 for communication purposes? Because of its important educational implications, this question has received considerable attention from theorists, researchers, and methodologists in the last decade. Traditionally, second language teaching methods were based on the assumption that learning a second language was equivalent to learning the L2 code and that, therefore, instruction that focused on the code (e.g., the learning of grammar rules in the Grammar Translation Method or the memorization of contextualized chunks of language in the Audiolingual Method) was the optimum methodology. However, in light of our growing understanding of the range of competencies that underlie language proficiency ${ }^{2}$ and the realization that knowledge about the L2 does not necessarily indicate the ability to function effectively in communication, the value and role of knowledge about the L2 code in developing L2 proficiency has been questioned. This paper will review the theories and research data that have accumulated with a view to evaluating whether a consensus is emerging which has specifiable instructional implications.

This issue of the role of formal knowledge about the L2 code has been investigated from two main perspectives: cognitive psychology and second language acquisition. First, in cognitive psychology, 
knowledge about the L2 is looked at from the perspective of its internal representation or structure in the learner's memory. Knowledge about the language is contrasted with knowledge of how to use the language effectively and efficiently in communication. In considering its role in language proficiency, the focus is on the processing mechanisms that lead to the initial internal representation and secondly, on the processes whereby this "know that" is transformed into "know how". The second perspective is one taken by SLA (second language acquisition) researchers who investigate the effects of instruction that focuses on the L2 code (form-focused instruction). In this framework, the focus is on the conditions (learner, input, and instructional strategy factors) that make formfocused instruction effective. Although these two perspectives overlap and interact in that theory on the mechanisms of internal processing has instructional implications and theory on instructional variables has implications for internal processes, it is important to distinguish between a learner's internal representation of information about the L2 code and the formalized public representation of knowledge about the L2 which is the content of form-focused instruction. It is quite possible that while knowledge about the L2 underlies proficiency, form-focused instruction is an ineffective way to develop that internal representation of knowledge about the language code.

A variety of positions have been taken regarding the L2 learner's representation of knowledge about the $\mathrm{L} 2$ code and the relation of that knowledge to performance ability. Some of these positions are based on theories of learning and expertise in cognitive science while some are specific to language learning. While terminology, concepts, and focus vary from paradigm to paradigm, what is common to all is the attempt to specify the relationship between knowing information and using that information productively in performance. Within an overall historical framework, these positions are outlined below beginning with Krashen's distinction between acquired and learned knowledge, moving to information processing views on the interaction of declarative and procedural knowledge, to Bialystok's specification of the analytic and control dimensions of declarative and procedural knowledge, and finally moving to the processes of expertise perspective regarding the use of knowledge by experts in performance and learning. Terms will be introduced as each position is developed and defined according to each theoretical paradigm. 


\section{ACQUIRED VERSUS LEARNED LANGUAGE KNOWLEDGE: TWO INDEPENDENT SYSTEMS}

Krashen $(1976,1981,1982,1985)$ has posited the existence of two independent systems or knowledge structures in adult SLA-subconscious language acquisition and conscious ${ }^{3}$ language learning. According to Krashen, subconscious language acquisition is the system responsible for fluent speech production in communication. Acquisition requires only meaningful interaction in the L2 (i.e., the focus is on meaning not on form) and takes place as a result of the learner having understood input that is a little beyond the current level of acquired knowledge $(i+1)$. The learner does not need to have any conscious knowledge (i.e., can be articulated) of language rules and any self-correcting is done on the basis of a "feel" for grammaticality. Conscious learning which includes the representation of formalized knowledge is available to the performer only as a monitor that may be applied before or after an utterance is spoken. Thus, knowledge about the code, in Krashen's view, is given an optional and very limited role in L2 proficiency development. The learner can only use this knowledge to edit language performance either before an utterance is spoken or after. As well, for this editing to occur, the learner must know the rule, focus on form not on meaning in the interaction, and have sufficient time. Krashen suggests that these conditions are unlikely to be met in most on-line communication, especially in the oral mode. To highlight how disruptive monitoring language form is to communication, Krashen (1985, p. 2) refers to an experimental study (Hulstijn \& Hulstijn, 1984) which reported that in a story-retell task, adult subjects cued to focus on form retold $14 \%$ less information and needed $30 \%$ more time than subjects cued to focus on content.

Krashen based his theory on preliminary second language acquisition research that indicated a similar sequence of acquisition of morphemes in L2 learners, a sequence that seemed to remain similar for L2 learners across age groups, L1 backgrounds, and learning environment. ${ }^{4}$ This position also draws support from SLA research evidence that suggests that a knowledge about the L2 code does not directly or necessarily transfer to the ability to function successfully in communication. For example, Krashen (Krashen \& Pon, 1975) cites the case of $P$, an educated and advanced ESL learner who had studied English for over twenty years but still made errors that involved simple rules in normal everyday conversations. In examining her errors, it was found that $\mathrm{P}$ could self-correct $95 \%$ of them and was able to explain the rule that was broken. As well, 
P wrote error-free English. Krashen argues that P's case indicates that in speech production the user does not access knowledge about the L2 code, while in writing the user can access this knowledge through monitor use.

\section{DECLARATIVE VERSUS PROCEDURAL KNOWDEDGE: TWO INTERACTING SYSTEMS}

General cognitive theories of learning also posit a dual representation of knowledge. Within the information processing framework of cognitive psychology, Anderson (1982, 1985) posits a theory of skill acquisition that distinguishes between declarative knowledge and procedural knowledge structures. ${ }^{5}$ According to Anderson's ACT (Adaptive Control of Thought) theory, new knowledge is stored (i.e., represented) in propositional form as declarative knowledge. Initial access to this declarative knowledge is slow and effortful in that it demands conscious (i.e., intentional) effort on the part of the learner. Through the process of proceduralization, the formal declarative knowledge is activated and deliberately put into operation in performance. Then, by means of repeated practice, the proceduralized knowledge is compiled (i.e., grouped into production sets) so that the productions trigger the needed behaviour without any intentional accessing of declarative knowledge. In this way, conscious knowledge is subsumed into unconscious skill. Behaviour that once was activated slowly and deliberately now is activated automatically, effortlessly, without conscious control or attention. These performance routines are developed through use-the use of declarative knowledge through activation, proceduralization, and compilation and the use of production sets through experience (i.e., practice) in performance.

Both Krashen and Anderson, then, posit a dual knowledge structure and relate this structure to performance skill. However, while in Krashen's model there is little productive interface between the "know that" structure and the "know how" structure, Anderson's model suggests that functional skill derives from formal declarative knowledge through practice.

The information processing view of skill learning has been applied to L2 learning. Various SLA researchers (McLaughlin, 1978; Bialystok, 1981b; Sharwood Smith, 1981; Ellis, 1984) have suggested the change from controlled processing to automatic processing is critical to the development of L2 proficiency. Controlled processing occurs when the learner is accessing "new" knowledge (potentially declarative knowledge about the L2 code) and effortfully applying it 
to a communication task. Automatic processing occurs when through practice, the knowledge or behavior previously subject to controlled processing has become routinized and automatic so that the learner no longer has to pay attention to, for example, word or structure choice. They further hypothesize that within this framework, instruction can serve two purposes: it can provide the learner with new declarative knowledge and it can provide the necessary practice that results in the automatization of this declarative knowledge. Accordingly, practice that focuses consistently on specific aspects of the L2 code (i.e., form-focused practice) may lead to the automatization of explicit knowledge about the code. However, as Sharwood Smith (1981) notes, learners must be prepared to "invest the extra time and energy to automatize what is currently exclusively explicit knowledge" (p. 165).

The role of practice in the development of L2 proficiency in an instructional setting has been the focus of several SLA studies. Seliger (1983) reported that in a study of the interaction patterns of L2 learners in a classroom, it was those who participated most frequently in classroom interactions that seemed to benefit the most in terms of increased L2 proficiency. However, Ellis (1984) investigated this issue in an experimental study and reported that while some L2 learners seemed to benefit more than others from form-focused instruction and practice, it was not the high interactors but the low interactors who benefitted. In his analysis of these results, Ellis examined the teacher-subject interactions further and suggested that rather than the quantity of interactions, it is the quality of interaction that seems to be important. In this study, those students who seemed to profit most from the form-focused drill practice were those who tried to communicate something meaningful in spite of the drill framework, those who actually negotiated meaning in their interaction with the teacher. This is similar to the conclusion that Long (1983b) draws from observational data of group interactions when he suggests that for an interaction to be useful for L2 acquisition, it must be an activity where there is an information gap so that the learners have to negotiate meaning in carrying out the task.

\section{ANALYZED KNOWLEDGE AND COGNITIVE CONTROL: TWO INTERACTING DIMENSIONS}

Still within this cognitive psychology model of information processing, Bialystok (1981a, b, 1982, 1990, 1991; Bialystok \& Ryan, 1985) has posited a model of the cognitive dimensions underlying 
language proficiency that aims to explain variability in learner proficiency as a function of the demands different tasks make on the learner's knowledge and abilities. Bialystok suggests that different language tasks (e.g., communication, metalinguistic) make different demands on the cognitive control and analyzed knowledge components of cognitive processing. This model represents an expansion of the constructs of declarative and procedural knowledge in the information processing model in that Bialystok posits that two processing components (analysis of knowledge and cognitive control) are involved in the operationalization of declarative and procedural knowledge for language use.

According to Bialystok (1990), "control is the process of selective attention to alternative or competing representations in on-line processing" (p. 48). Cognitive control is essentially an access mechanism that includes the functions of selection and coordination, and automaticity or fluency in carrying out these functions. Control in selection and coordination relates to the ability to focus differentially on the form or meaning aspects of language according to task and processing demands, and to coordinate and integrate these language resources with other knowledge resources such as context and world knowledge. Fluency develops as a result of increasing skill (i.e., the development of automatized procedures) in the selection and integration of appropriate information for language processing tasks. As a learner's fluency increases, the demands on the attentional resources required for controlled processing decrease leaving available to the learner cognitive capacity for higher level processing. Inversely, the less fluent a learner is on a given task, the more demands there are on the cognitive control processes of selection and coordination. This is where a learner's strategic competence becomes important in that the learner may compensate for gaps in knowledge and/or automaticity by advanced strategic control procedures.

The dimension of analyzed knowledge refers to the explicitness of the internal representation of language information by a learner. Analyzed knowledge (explicit knowledge) is information whose structure is mentally represented and organized in a way that allows the learner to manipulate (explain, compare, evaluate, transform) and use it creatively across a range of contexts. Moreover, a high level of analysis is associated with the ability to access knowledge to consciousness and articulate its structural principles. Unanalyzed knowledge (implicit knowledge) is information whose structure the learner has not analysed, and therefore, the learner has limited access to it and its use is tied to particular contexts of routine use. 
The formulas, chunks, and patterns that an L2 learner learns in the early stages of L2 learning are examples of knowledge at the unanalyzed end of the continuum, while the advanced learner's ability to justify a word or tense choice is an example of knowledge at the analyzed knowledge end of the continuum. Essentially, analyzed knowledge relates to the coherence and connectedness of declarative and procedural knowledge representations. So, for example, formalized information about language such as a verb conjugation may be represented by the learner in an analyzed or unanalyzed way. It is represented in an unanalyzed way if it is not connected with the learner's existing structure in a meaningful and richly elaborated manner such as if it is memorized as an isolated chunk rather than integrated into a schema with verbs of a similar pattern.

According to Bialystok's framework, progression in L2 proficiency can be interpreted as a move from a largely unanalyzed representation of knowledge about the L2 to an increasingly analyzed representation and from a processing mode where control is exerted on base skill processes because of a lack of automaticity to a processing mode where the base skill processes are highly automated and control is exerted on higher level cognitive functioning.

In terms of the present discussion regarding the value of knowledge about the L2 in developing L2 proficiency, Bialystok's framework has several implications. First, the knowledge the learner has about the L2 is important in proficiency. Bialystok argues that the critical problem for L2 learners is to develop an analyzed knowledge of the L2 so that they are able to function flexibly across a wide range of tasks. In particular, the literacy functions of reading and writing demand high levels of analyzed knowledge because in these functions the language elements themselves rather than the situational context carry the main burden of creating meaning and, as well, subtle distinctions in form/meaning relationships are made for specific and creative meaningconstruction purposes. Bialystok suggests that a learner's level of analyzed knowledge about the L2 can be increased by the experience of doing tasks that demand higher levels of analyzed knowledge than the learner currently possesses and by instruction, if the learner is "ready", that is, is on the verge of insight regarding this information. This recalls Krashen's ( $i+1)$ hypothesis regarding the learner's readiness to "acquire" a language rule. As well, recent SLA research (Pienemann, 1984; Lightbown \& Spada, 1989) offers some support for this claim. 
Within the paradigm of developmental L2 learning, Pienemann $(1984,1985)$ has made several hypotheses regarding the teachability of language forms. According to this paradigm (Meisel et al., 1981), psycholinguistic constraints account for the observed similarities in the stages L2 learners pass through in the acquisition of certain syntactic structures (e.g., interrogation,negation). In second language acquisition, two types of linguistic features are distinguished-developmental and variational. Developmental features (e.g., word order rules) are features whose acquisition depends on the prior development of relevant language processing mechanisms. Specifically, the acquisition of developmental features is posited to proceed sequentially according to the complexity of the cognitive operations involved; syntactic structures requiring simple cognitive operations are acquired before those requiring complex operations. In contrast, variational features (e.g., copula "be") are linguistic features whose acquisition are not developmentally constrained but rather depend on psychosociological factors (e.g., learner attitude, motivation, and social integration).

Within this framework, Pienemann argues that while variational features are amenable to instruction, developmental features generally are not amenable to instruction ahead of their natural order. However, if a learner is ready developmentally, instruction can benefit acquisition. He based these hypotheses on experimental research investigating the effects of instruction on the acquisition of German by L2 children. Pienemann $(1984,1985)$ found that while instruction increased the use of the variational feature "copula", it did not alter the sequence of acquisition of the developmental feature, German word order (adverb, particle, and inversion). However, if a learner demonstrated evidence of the use of a given stage of word order rule use, then instruction affected the speed of acquisition, the frequency of rule application, and the range of contexts in which the rule was used.

This position is further supported by evidence reported by Lightbown and Spada (1990). Reporting on classroom observation data, they noted that in a communicatively oriented L2 instructional program, groups of francophone ESL students who received contextualized form-focused instruction demonstrated higher levels of appropriate use and accuracy (progressive -ing; there is) and were at a more advanced stage in use for some targeted structures (possessive determiners) than groups who received little or no formfocused instruction.

Secondly, Bialystok's model suggests that since different language tasks make differential demands on the analyzed knowledge and 
cognitive control dimensions, some instructional strategies and learning tasks may lead to the development of certain aspects of language proficiency more effectively than others. There is some support for this hypothesis among SLA theorists and researchers. For instance, Higgs and Clifford (1982) argue that while adult L2 learners may acquire high levels of fluency in learning contexts where the focus is on meaning and communication, such contexts do not lead to the development of accuracy. Rather the development of accuracy in adult L2 learners is enhanced by directing the learner to focus on aspects of the formal system of the L2. Similarly, Swain $(1985,1988)$ reporting on learning outcomes in French immersion programs suggests that while content-based L2 instruction may lead to native-like comprehension abilities and high levels of fluency, a different type of instruction is needed to develop an accurate and advanced level of proficiency (subtle lexical and structural distinctions over a wide range of functions). To achieve this, L2 learners need instruction which focuses them on form-function relationships (i.e., formal knowledge about these relationships), which requires them to experience oral and written production tasks, and which provides appropriate corrective feedback on this use. Swain suggests that this type of form-focused instruction enhances language acquisition because it encourages learners to consciously reflect on (i.e., notice and potentially understand) the relationship between linguistic form and its meaningful realization in communication.

Thirdly, Bialystok's model suggests that in the control dimension, the main effort for adult L2 learners is to develop automaticity through experience (practice) since they have already developed a variety of cognitive control mechanisms for L1 functioning. Moreover, the previously acquired control knowledge and skill function as resources to help compensate for lack in automaticity and/or analyzed knowledge. Research into the strategic resources L2 learners use has confirmed the value of these cognitive control processes in both L2 learning and use. L2 learners have been shown to use a variety of communication strategies (e.g., avoidance, literal translation, paraphrase) in conversation to communicate beyond their level of competence (Tarone, 1980; Faerch \& Kasper, 1984). In addition, a variety of effective learning strategies (e.g., planning, monitoring, inferencing) used by L2 learners to facilitate the internalization and automatization of L2 knowledge have been identified (Wenden \& Rubin, 1987). Furthermore, this research in strategy use by L2 learners indicates that L2 learners who lack certain control skills benefit from direct instruction in the what, 
how, and when of strategy use in various skill areas: vocabulary acquisition (Cohen \& Aphek, 1980), listening (O'Malley, 1987), speaking (O’Malley, 1987), reading (Carrell, 1985; Kern, 1989).

The importance of the cognitive control dimension in SLA has also been demonstrated by Hulstijn $(1984,1989)$. By manipulating attention (focus on grammatical form versus focus on meaning), Hulstijn was able to affect learning outcomes. In one experimental study (1984), learners of Dutch as an L2 who were instructed to focus on grammar made a more accurate use of two word order rules in a story retell task than learners instructed to focus on the meaning. This outcome was observed regardless of the learners' explicit knowledge or lack of knowledge of the appropriate rules. In a more recent study (1989), Hulstijn again manipulated the attention on form versus meaning factor. In this study, he controlled for prior knowledge, first by using structures that are difficult for L2 learners of Dutch, and then by using artificial target structures. In both treatments, on a cued recall task, form-focused learners showed a more accurate use of targeted grammatical structures while meaning-focused subjects had a better recall of content. These studies underline the importance of attention or what Bialystok labels the cognitive control dimension in SLA and, furthermore, suggest that some significant learning of L2 structures can occur at the point of input encoding in communication, if the learner is attending to form.

\section{THE LEARNING PROCESSES EXPERTS ENGAGE IN: AN INTERACTION OF KNOWLEDGE}

Another area in cognitive psychology that has explored the learner's internal representation of knowledge and its relation to performance is research into the nature of expertise. The goal of expert processes research has been to characterize differences in expert/novice performance (more versus less skilled) in terms of knowledge, skill, and problem solving processes. Overall, this research (summarized in Lesgold, 1983; Chi et al., 1988) has demonstrated that experts in a domain know more, their knowledge is more elaborately and coherently organised, they have a higher level of skill automatization and more effective control processes, and they create better problem representations of a situation than novices do.

In addition, this research adds another dimension to the issue of the role of knowledge about the $\mathrm{L} 2$ in developing proficiency. Research examining expert/novice knowledge differences indicates 
that there are qualitative differences in the knowledge structures experts use in performance compared to novices. A key distinction is made between formal and informal knowledge structures.

Formal knowledge in this theoretical framework is the conscious, explicit knowledge (i.e., can be articulated) the learner has of the facts and theory of a specific domain. In the L2 context, it is the conscious knowledge the learner has of the L2 language code-words and their meaning, sounds, and structures. This formal knowledge can be acquired either through studying the formalized public representation of domain knowledge in books or by abstracting information from relevant case experience. In contrast, informal knowledge is the implicit knowledge that is incidently acquired (i.e., without intentional effort) through contextualized functioning in the domain. Children's knowledge of their native language prior to schooling is a prime example of informal knowledge in the domain of language. As well, it is the implicit, informal knowledge of adult native language users that modern linguistics tries to tap and describe as the basis of the scientific description of a language.

Research into expert processes in task performance (problemsolving tasks) suggests that in performance experts function on the basis of their informal knowledge rather than their formal knowledge. Since in performance, time and processing constraints preclude much consultation with formal knowledge, expertise resides in informal knowledge and skill that is ready for action rather than formal thinking knowledge. In the domain of language, this suggests a similar hypothesis as that suggested by Krashen-namely that communication, that is, language performance, operates from informal, "acquired" knowledge that is developed through situated use rather than from formal, "learned" knowledge. However, this expert process research does not follow Krashen's conclusion that, therefore, the only knowledge representation useful for language learning is informal knowledge. The fact that some essential language learning occurs through engagement in meaningful communication (i.e., use), does not necessarily imply that language learning occurs only in this way. Instead, expert processes theory suggests that while formal knowledge may play a limited role in online performance, in the acquisition of expertise, formal knowledge has a significant role to play.

Bereiter \& Scardamalia (1989) have posited a model of expert processing that suggests that one of the key characteristics of expert behaviour is that experts problem solve in a progressive way in that they continually reinvest freed up cognitive resources to problem 
solve in their targeted domain to achieve higher and higher levels of knowledge and skill. This reinvestment of cognitive resources shows up in the constructive knowledge building and knowledge transforming processes expert learners engage in. Expert learners actively engage in a dialectic between formal and informal knowledge structures. Experts construct formal knowledge and transform that formal knowledge into informal functional knowledge through progressive problem solving in contextualized use. In addition, experts use informal case knowledge to solve formal knowledge problems; experts are aware of the gaps, limits of their knowledge and they use particular cases to solve these problems and in doing so transform their formal knowledge structure.

Differences in constructive problem solving processes have been shown to affect knowledge and skill proficiency outcomes in L2 learners. In a study of expert/novice differences in L2 writing, Cumming (1988) found that expert L2 writers focused on language choice in a qualitatively different way than novices. While novices focused on linguistic accuracy (spelling verification and the application of grammar rules), experts conducted extensive searches (one search lasted six minutes) for the word(s) to best convey the intended meaning and considered connotation, appropriateness and purpose, as well as linguistic accuracy. These learners seemed to call on their formal knowledge about the L2 to solve immediate communication of content problems. Cumming suggested that these expert L2 writers were using the occasion of a writing task to integrate their knowledge in a content field with their knowledge about the L2. This added attention to language form/function relations allowed them to store "new" connections in memory and thus, learn language through writing.

In another study, Corbeil (1989) investigated L2 learner processes in response to error feedback in an instructional setting. She noted differences in the processes more versus less successful learners engaged in vis $\grave{a}$ vis error correction: "... successful students attempt to identify elements of information, to explore related forms, to establish connections between existing and new knowledge, to resolve discrepancies between these two sources of information, and to make up hypothetical rules. Less successful students seem to. . . avoid teacher's corrections, to repeat the corrections although inaccurately or incompletely, and on rare occasions, to repeat teacher's corrections accurately but without signs of understanding" (p. 56). This suggests that some L2 learners use teacher corrections (specific case information) to qualify or transform their formal knowledge of a rule governing a language element. Moreover, 
Corbeil suggested that use of elaborate knowledge construction and knowledge transforming processes related to improved L2 learning in that these processes were invariably used by the more successful students and significantly, less successful students could productively be taught to use these strategies via a direct explanation and modelling instructional strategy.

These studies of expertise provide some beginning evidence of how expert L2 learners actually make use of their L2 knowledge to learn and expand both their knowledge about the L2 and their skill proficiency. In addition, within this perspective of the problem solving nature of L2 learning, several hypotheses have been posited by SLA researchers regarding the potential role of error correction as a form-focused instructional strategy.

Corder (1981) posited that form-focused instruction in the form of corrective feedback enhances the hypothesis testing or problem solving activity of the L2 learner. In this view, language learning is seen as a problem solving activity and one of the goals of learners is to test out current hypotheses about the L2 formal system and how it functions in communication to advance their formal knowledge structure. The role of form-focused corrective feedback is to direct and motivate learners to do the appropriate processing to restructure their knowledge representation. Herron \& Tomasello (1988) and Tomasello \& Herron (1990) have investigated this in two experimental instructional studies. In one study (1988), they examined the learning of grammatical structures in two instructional treatment conditions (feedback versus modelling); subjects in the feedback condition were directed through a self-correction process while those in the modelling treatment only listened to appropriate examples of the target item. In another study (1990), they investigated the effects of two instructional strategies (presentation and explanation of the exceptions versus correction of induced errors) on the learning of eight "exception to the rule" grammatical structures. Results in both experiments confirm the superior performance of learners who in instructional settings were encouraged to engage in focused problem solving regarding the use of specific L2 forms rather than instruction where the structures were part of the input and their form and functions were only modelled or explained.

Within the linguistic paradigm of universal grammar (UG), White $(1985,1990)$ offers a different view regarding the potential value of form-focused instruction in SLA. UG theory holds that language learning is mediated by a learner's internal grammar which consists of innate properties of grammar (universals), as well as expectancies 
based on the learner's existing language knowledge (both L1 and L2). White argues that instruction in the form of corrective feedback may be needed to disconfirm faulty hypotheses about the L2 that learners hold based on a transfer of L1 expectancies. White (1990) reported on an experimental study that looked at the learning of English adverb placement rules by francophone learners. Although there are overall similarities between the adverb placement rules in the two languages, there are subtle differences. For example, in English but not in French, adverbs can be placed between the subject and verb (e.g., SAV: Mary often swims); and in French but not in English, adverbs can be placed before the direct object (e.g., SVAO: Marie boit souvent du cafe). In natural input, French ESL learners will get evidence for the SAV placement; however, they will never get evidence that SVAO is not permitted. White posited that for these francophone learners to learn that SVAO is not permitted form-focused instruction may be needed. Results of an experimental study suggested that in judgement and production tasks, instructed students (i.e., students who had SVAO errors corrected and explained) rejected SVAO placement while uninstructed learners did not. According to this view then, the role of form-focused instruction is to direct the learner's attention to incorrect L1-based rule representation and guide the learner to restructure this internal representation.

\section{A CONSENSUS OF EMERGING VIEWPOINTS}

In reviewing the theories and data that address the issue of the role of knowledge about the L2 in developing proficiency, one is struck by the variety of theoretical and research paradigms that have focused on this issue. Their diversity underlines the complexity inherent in trying to explain first, how a learner's knowledge affects proficiency development and secondly, the even more complex problem of how a formalized presentation of knowledge about the L2 (i.e., form-focused instruction) affects the learner's internal representation of that knowledge. Nonetheless, in the last decade, our understanding of this issue has increased. In spite of differences in theoretical focus, methodology, and terminology, and the piecemeal nature of the findings so far, a consensus is emerging which although not comprehensive or detailed provides a viable framework for educators to work within and highlights specific issues for future research. Even though the knowledge the learner has about the L2 code plays a limited role (monitoring or planning functions) in actual communication due to time and processing 
constraints (Krashen 1981, 1985; Bereiter \& Scardamalia, 1989), theory and evidence from all perspectives suggests that this code knowledge does play a significant role in the development of proficiency.

First, skill acquisition theory (Anderson 1982, 1985) indicates that one of the key routes in the development of automated skill is the transformation of declarative knowledge "know about" into proceduralized "know how". This occurs through the conscious (i.e., intentional) activation and operationalization of declarative knowledge by means of repeated practice. The instructional issue here concerns the type of practice that effectively leads to automated skill development at the various stages of proficiency. Ellis (1988) in reviewing research that examines the role of practice in L2 classroom learning concludes that there is no clear evidence that code-focused practice directly promotes SLA and that "practice may only facilitate acquisition directly if it is communicative, i.e., meaning-focused in nature" (p. 38). SLA research findings (Ellis, 1984; Long, 1983b) underline the importance that this practice be meaningful in the sense that the learner is actually engaged in the interpretation and construction of meaning. This concern is similarly reflected in the expert processes perspective where the importance of informal functional knowledge in performance is highlighted. Expertise in performance resides in the learner's functional knowledge base which is acquired through situated use, that is, meaningful communication in the L2. In addition, current SLA theory emphasizes the importance of this practice being authentic so that the learner gains the necessary experience in the access, selection, and co-ordination of the relevant information and in the procedures required in complex language functioning.

However, while form-focused practice may not directly impact on acquisition, it may serve an enabling function. It is quite likely that at the beginning stages of skill development focused instruction and practice to automatize certain enabling skills is effective (Fredrickson et al., 1985; McLaughlin, 1990). For example, in L2 reading skill development, a typical procedural problem of the low proficiency learner is the tendency to read word-by-word. Teaching these students a procedure for using their syntactic knowledge to group words and to focus on reading in those word groupings is one potential way to develop automaticity in sentence parsing, an enabling skill in reading proficiency. Moreover, Ellis (1988) hypothesizes that focused code practice may allow the learner to develop declarative knowledge by raising the learner's awareness of formal properties of the L2. This declarative knowledge may have a 
delayed facilitating effect on L2 acquisition in the sense that it enables learners to attend to formal features of the input that they otherwise might not have become aware of, thus promoting the later acquisition of the focused-upon language item.

Secondly, the learner's knowledge about the L2 is important for the development of certain aspects of an advanced and flexible L2 proficiency. Different language functions and tasks make differential demands on the knowledge the learner has about the L2 (Bialystok, 1985). While routinized daily oral communication may make little demand for analyzed knowledge, the literacy functions of reading and writing demand higher levels of analyzed knowledge. Moreover, for the adult L2 learner analyzed knowledge of the L2 code can provide a framework for interpreting and integrating new information about the L2 (Corbeil, 1989; Cumming, 1988). As well, this analyzed knowledge is important in the development of accurate production proficiency (Higgs \& Clifford, 1982; Swain, 1985, 1988). This suggests that instructional programs need to provide the learner with a variety of language communication experiences to cover a wide enough range of functions to ensure adequate proficiency development.

Another instructional issue that this raises is how to develop a learner's analyzed knowledge and whether the presentation of formalized knowledge about the L2 affects the learner's internal representation. In the theory and research reviewed in this paper, there is no evidence that the traditional presentation of formalized book knowledge about the L2 is seen to be an effective instructional strategy. ${ }^{6}$ Rather researchers are exploring different ways to alert the L2 learner to formal features of the L2 code in contexts where this knowledge about the L2 code is relevant to needs-either developmental needs (Pienemann, 1984; White, 1985), task needs (Bialystok, 1985; Swain, 1988), or L2 code gaps (White, 1985; Herron \& Tomasello, 1988; Tomasello \& Herron, 1990). The key seems to be to motivate and guide the learner to attend to aspects of the L2 code at times and in ways that will lead to a restructuring (McLaughlin, 1990) of the learner's internal representation. Overall, the research to date seems to suggest:

1. some learning of code features occurs unintentionally at the point of input encoding in communication as long as the learner is attending to form (Hulstijn \& Hulstijn, 1984; Hulstijn, 1989);

2. some aspects of the code (variational rather than developmental features) may be more amenable to instruction than others and 
developmental features may be "teachable" if the learner has reached the prerequisite stage in L2 development (Pienemann, 1984, 1985);

3. instructor feedback on errors is potentially one form-focused instructional strategy that can motivate and guide the learner to the necessary restructuring (Tomasello \& Herron, 1990; White, 1990);

4. another potentially effective instructional strategy is to embed form-focus in the communication task itself so that the learner's attention is naturally drawn to aspects of the L2 code according to task demands and the realization knowledge gaps (Swain, 1988);

5. and finally, the L2 learner can be taught learning strategies that will allow for an effective exploitation of communication events not only to develop skill proficiency (Carrell, 1985; O'Malley, 1987) but also to increase knowledge about the L2 code (Corbeil, 1989).

\section{NOTES}

1. Knowledge about the L2 code here refers to the learner's internal representation of knowledge about the second language linguistic system including the phonological, morphological, syntactic, and lexical systems.

2. For example, Van Ek (1990) describes L2 proficiency as consisting of linguistic, sociolinguistic, discourse, strategic, social, and socio-cultural competencies.

3. The concept of consciousness has been used with different meanings in various theoretical paradigms. As Schmidt (1990) observes, consciousness in learning may refer to awareness as in noticing and potentially understanding, to intention as in deliberate and effortful attention, or to knowledge in the sense of explicit knowledge one can manipulate and potentially articulate. When the term is used in this paper, its specific sense in each context will be indicated.

4. The theoretical and empirical basis of Krashen's theory has been seriously questionned (e.g. McLaughlin, 1978, 1987; Gregg, 1984). Krashen's theory has been criticized because of ill-defined terms, circular arguments, lack of empirical evidence, and lack of precise testable hypotheses. As well, the methodological design of 
the early morpheme studies has been criticized and later empirical research has contradicted these earlier results. For example, individual variation in patterns of morpheme acquisition have been found to depend on such factors as subject's L1, the frequency of forms in input, and differences in learning strategy.

5. Anderson's ACT theory represents a comprehensive integration of theory and experimental research data in cognitive psychology that has accumulated over the last two decades.

6. Schmidt (1990) reaches a similar conclusion in his analysis of psychological theory and research on the role of consciousness in L2 learning.

\section{ACKNOWLEDGEMENTS}

The author would like to thank Dr. Merrill Swain, Dr. Ellen Bialystok, and the anonymous TESL Canada reviewers for their constructive feedback on a preliminary draft.

\section{THE AUTHOR}

Carol Fraser is an Assistant Professor of ESL at Glendon College, York University where she prepares francophone students to take content courses in English. She is interested in L2 reading and writing processes in academic contexts, the types of instructional interventions that affect proficiency development, and assessment methods. She is co-developer of the Glendon Examination of Bilingual Competence and has published articles in the areas of test development, and reading/writing instruction. She is presently working on a Doctorate at O.I.S.E. in the area of language education.

\section{REFERENCES}

Anderson, J. R. (1982). Acquisition of cognitive skill. Psychological Review 89, 369-406.

Anderson, J. R. (1985). Cognitive psychology and its implications. New York: W. H. Freeman. 
Bereiter, C. \& Scardamalia, M. (1989). Expertise as process. Unpublished manuscript. Centre for Applied Cognitive Science, OISE.

Bialystok, E. (1981a). The role of linguistic knowledge in second language use. Studies in Second Language Acquisition 4, 31-45.

Bialystok, E. (1981b). Some evidence for the integrity and interaction of two knowledge sources. In R. Anderson (Ed.), New dimensions in SLA research. Rowley, MA: Newbury House.

Bialystok, E. (1982). On the relationship between knowing and using linguistic forms. Applied Linguistics 3, 181-206.

Bialystok, E. (1990). The dangers of dichotomy: A reply to Hulstijn. Applied Linguistics 11, 46-51.

Bialystok, E. (1991). Achieving proficiency in a second language: A processing description. In R. Phillipson, E. Kellerman, M. Sharwood Smith, \& M. Swain (Eds.), Foreign/second language pedagogy research. Clevedon, England: Multilingual Matters.

Bialystok, E. \& Ryan, E. B. (1985). A metacognitive framework for the development of first and second language skills. In $\mathrm{D}$. $\mathrm{L}$. Forrest-Pressley, G. E. MacKinnon, \& T. G. Waller, (Eds.), Metacognition, cognition, and human performance (pp. 207-252). Orlando: Academic Press.

Birdsong, D. (1989). Metalinguistic performance and interlinguistic competence. Berlin, West Germany: Springer-Verlag.

Carrell, P. L. (1985). Facilitating ESL reading by teaching text structure. TESOL Quarterly 19, 727-752.

Chi, M., Glaser, R. \& Farr, M. (1988). The nature of expertise. Hillsdale, New Jersey: Lawrence Erlbaum Associates.

Cohen, A. \& Aphek, E. (1980). Retention of second-language vocabulary over time: investigating the role of mnemonic associations. System 8, 221-235.

Corbeil, G. (1989). Adult second language learners: fostering high levels of constructive processes in response to corrective feedback. Unpublished doctoral dissertation, OISE, Toronto.

Corder, S. P. (1981). Error analysis and interlanguage. Oxford: Oxford University Press.

Cumming, A. (1988). Writing expertise and second language proficiency in ESL writing performance. Unpublished doctoral dissertation, OISE, Toronto.

Ellis, R. (1984). Can syntax be taught?: A study of the effects of formal instruction on the acquisition of WH questions in children. Applied Linguistics 5, 138-153.

Ellis, R. (1986). Understanding second language acquisition. London: Oxford University Press. 
Ellis, R. (1988). The role of practice in classroom learning. AILA Review 5, 20-39.

Ellis, R. (1990). Instructed second language acquisition. London: Basil Blackwell.

Faerch, C. \& Kasper, G. (1984). Two ways of defining communication strategies. Language Learning 34, 45-63.

Frederiksen, J. R., Warren, B. M. \& Rosebery, A. S. (1985). A componential approach to training reading skills: Part 1. Perceptual Units Training. Cognition and Instruction 2, 91-130.

Gregg, K. (1984). Krashen's monitor and Occam's razor. Applied Linguistics 5, 79-100.

Harley, B. \& Swain, M. (1985). The interlanguage of immersion students and its implications for second language teaching. In A. Davies \& C. Criper (Eds.), Interlanguage (pp. 291-311). Edinburgh: Edinburgh University Press.

Herron, C. \& Tomasello, M. (1988). Learning grammatical structures in a foreign language: Modelling versus feedback. French Review 61, 910-922.

Higgs, T. \& Clifford, R. (1982). The push toward communication. In T. Higgs (Ed.), Curriculum, competence and the foreign language teacher. ACTFL Foreign Language Education Series. National Textbook Company.

Hulstijn, J. (1990). A comparison between the informationprocessing and the analysis/control approaches to language learning. Applied Linguistics 11, 30-45.

Hulstijn, J. \& Hulstijn, W. (1984). Grammatical errors as a function of processing constraints and explicit knowledge. Language Learning 34, 23-44.

Hulstijn, J. (1989). Implicit and incidental second language learning: Experiments in the processing of natural and partly artificial input. In $H$. W. Dechert \& M. Raupach (Eds.), Interlingual processes (pp.49-73). Tübingen: Günter Narr Verlag.

Kern, R. G. (1989). Second language reading strategy instruction: Its effects on comprehension and word inference ability. Modern Language Journal 73, 135-148.

Krashen, S. (1976). Formal and informal linguistic environments in language learning and language acquisition. TESOL Quarterly 10, 157-168.

Krashen, S. (1981). Second language acquisition and second language learning. Oxford: Pergamon Press.

Krashen, S. (1982). Principles and practice in second language acquisition. Oxford: Pergamon Press. 
Krashen, S. (1985). The input hypothesis: issues and implications. London: Longmans.

Krashen, S. \& Pon, P. (1975). An error analysis of an advanced ESL learner: The importance of the monitor. Working Papers on Bilingualism 7, 125-129.

Lesgold, A. (1983). Acquiring expertise. In J. R. Anderson \& S. M. Kosslyn (Eds.), Tutorials in learning and memory: Essays in honor of Gordon Bower. San Francisco: W. H. Freeman.

Lesgold, A. \& Glaser, R. (1989). Foundations for a psychology of education. Hillsdale, New Jersey: Lawrence Erlbaum Associates.

Lightbown, P. (1985). Can language acquisition be altered by instruction? In K. Hyltenstam \& M. Pieneman (Eds.), Modelling and assessing second language acquisition (pp. 101-111). San Diego, CA: College-Hill Press.

Lightbown, P. \& Spada, N. (1990). Focus-on-form and corrective feedback in communicative language teaching: Effects on second language learning. Studies in Second Language Acquisition 12, 429-448.

Long, M. (1983a). Does second language instruction make a difference? A Review of research. TESOL Quarterly 17, 359-382.

Long, M. (1983b). Native speaker/non-native speaker conversation and the negotiation of comprehensible input. Applied Linguistics 4, 126-141.

Long, M. (1985). A role for instruction in second language instruction: Task-based language teaching. In K. Hyltenstam \& M. Pienemann (Eds.), Modelling and assessing second language acquisition (pp. 83-96). San Diego, CA: College-Hill Press.

McLaughlin, B. (1978). The monitor model: Some methodological considerations. Language Learning 28, 309-332.

McLaughlin, B. (1987). Theories of second-language learning. London: Edward Arnold.

McLaughlin, B. (1990). Restructuring. Applied Linguistics 11, 113128.

McLaughlin, B., Rossman, T. \& McLeod, B. (1983). Secondlanguage learning: An information-processing perspective. Language Learning 33, 135-158.

Meisel, J., Clahsen, H. \& Pieneman, M. (1981). On determining developmental stages in natural second language acquisition. Studies in Second Language Acquisition 3, 109-135.

O'Malley, J. M. (1987). The effects of training in the use of learning strategies on acquiring English as a second language. In A. Wenden \& J. Rubin (Eds.), Learner strategies in language learning. Englewood Cliffs, NJ: Prentice-Hall International. 
Pienemann, M. (1984). Psychological constraints on the teachability of languages. Studies in Second Language Acquisition $6,186-214$.

Pieneman, M. (1985). Learnability and syllabus construction. In $\mathrm{K}$. Hyltenstam \& M. Pieneman (Eds.), Modelling and assessing second language acquisition. San Diego, CA: College-Hill Press.

Schmidt, R. W. (1990). The role of consciousness in second language learning. Applied Linguistics 11, 130-158.

Seliger, H. (1983). Learner interaction in the classroom and its effect on language acquisition. In $\mathrm{H}$. Seliger \& M. Long (Eds.), Classroom oriented research in second language acquisition. Rowley, MA: Newbury House.

Sharwood Smith, M. (1981). Conscious-raising and the second language learner. Applied Linguistics 11, 159-168.

Spada, N. \& Lightbown, P. (1990). Form-focus in L2 teaching: Drops of oil on water? Paper presented at AILA 1990, Thessalonika, Greece.

Swain, M. (1985). Communicative competence: Some roles of comprehensible input and comprehensible output in its development. In S. Gass \& C. Madden (Eds.), Input and second language acquisition (pp. 235-253). Rowley, MA: Newbury House.

Swain, M. (1988). Manipulating and complementing content teaching to maximize second language learning. TESL Canada Journal 6, 68-83.

Tarone, E. (1980). Communication strategies, foreigner talk, and repair in interlanguage. Language Learning 30, 417-431.

Tomasello, M. \& Herron, C. (1990). Down the garden path: Inducing and correcting overgeneralization errors in the foreign language classroom. Applied Psycholinguistics 9, 237-246.

Van Ek, J. (1990). Objectives for foreign language learning and teaching. Journal of Applied Linguistics 6, 86-96.

Wenden, A. \& Rubin, J. (1987). Learner strategies in language learning. Englewood Cliffs, NJ: Prentice-Hall International.

White, L. (1985). Is there a "logical problem" of second language acquisition? TESL Canada Journal 2, 29-41.

White, L. (1990). Adverb placement in SLA: The effects of positive and negative evidence in the classroom. Paper presented at AILA 1990, Thessalonika, Greece. 